\title{
A MEDIAÇÃO COMUNITÁRIA COLABORATIVA: NOVAS PERSPECTIVAS PARA EDUCAÇÃO EM MUSEUS
}

\author{
COLLABORATIVE COMMUNITY MEDIATION: \\ NEW PERSPECTIVES FOR MUSEUM EDUCATION
}

\author{
LA MEDIACIÓN COMUNITARIA COLABORATIVA: \\ NUEVAS PERSPECTIVAS PARA LA EDUCACIÓN EN MUSEOS
}

Camilo de Mello Vasconcellos ${ }^{1}$; Maurício André da Silva ${ }^{2}$

\begin{abstract}
RESUMO
Nas últimas décadas os museus adotaram novas agendas e pautas, especialmente no diálogo com seu entorno e diferentes públicos. Nesse sentido, parcelas da sociedade em contextos de vulnerabilidade social vêm ganhando espaço no interior das instituições, redefinindo suas metas, planejamentos e prioridades. Este artigo reflete sobre o trabalho educativo desenvolvido pelo Museu de Arqueologia e Etnologia da Universidade de São Paulo com um grupo de crianças da comunidade São Remo (favela com 12 mil habitantes, vizinha à Universidade) por meio da mediação comunitária colaborativa. Desde 2014 novas ações vêm sendo realizadas buscando, por um lado, diminuir as distâncias simbólicas e reais entre o Museu e sua vizinhança imediata e, por outro, ampliar o papel social, político e educativo da instituição.
\end{abstract}

PALAVRAS-CHAVE: Museu. Educação em museus. Mediação comunitária colaborativa e Públicos inclusivos.

\begin{abstract}
In the last decades, museums have adopted new agendas and guidelines, especially in the dialogue with their surroundings and different public. In this sense, portions of society in contexts of social vulnerability have been gaining ground within institutions, redefining their goals, planning and priorities. This article reflects on the educational work developed by the Museum of Archeology and Ethnology of the University of São Paulo with a group of children from the São Remo community (a "favela"* with 12,000 inhabitants, neighbor to the University) through collaborative community mediation. Since 2014, new actions have been carried out aiming, on the one hand, to reduce the symbolic and real distances between the Museum and its immediate neighborhood and, on the other hand, to amplify the social, political and educational role of the institution.
\end{abstract}

KEYWORDS: Museum. Museum education. Collaborative community mediation and Inclusive public.

\footnotetext{
${ }^{1}$ Doutorado em História - Universidade de São Paulo (USP) - São Paulo, SP - Brasil. Professor Doutor - Museu de Arqueologia e Etnologia da Universidade de São Paulo (MAE/USP) - São Paulo, SP - Brasil. E-mail:

cmvasco@usp.br

${ }^{2}$ Doutorando em Arqueologia e Mestre em Arqueologia - Museu de Arqueologia e Etnologia da Universidade de São Paulo (MAE/USP) - São Paulo, SP - Brasil. Educador - Seção Técnica de Educação para o Patrimônio (STEP) do Museu de Arqueologia e Etnologia da USP (MAE/USP) - São Paulo, SP - Brasil. E-mail: mau.mata@gmail.com
}

Submetido em: 13/02/2018 - Aceito em: 05/06/2018

(C) ETD- Educação Temática Digital Campinas, SP $\quad$ v.20 $\quad$ n.3 $\quad$ p. 623-639 jul./set. 2018




\section{RESUMEN}

En las últimas décadas los museos adoptaron nuevas agendas y pautas, especialmente en el diálogo con su entorno y diferentes públicos. En ese sentido, una parte de la sociedad, en contextos de vulnerabilidad social, gana espacio dentro de las instituciones y se redefine sus metas, planificaciones y prioridades. Este artículo refleja sobre el trabajo educativo desarrollado por el Museo de Arqueología y Etnología de la Universidad de São Paulo con un grupo de niños de la comunidad São Remo (favela con 12 mil habitantes, vecina a la Universidad) a través de la mediación colaborativa. Desde 2014 nuevas medidas están siendo realizadas buscando, por una parte disminuir las distancias simbólicas y reales entre el Museo y su vecindario inmediato y, por otra ampliar el papel social, político y educativo de la institución.

PALAVRAS-CLAVE: Museo. Educación en museos. Mediación comunitaria colaborativa y Públicos inclusivos.

\section{MEDIAÇÃO COMUNITÁRIA COLABORATIVA NO CONTEXTO MUSEOLÓGICO COMO CAMPO DE ATUAÇÃO}

Tradicionalmente as práticas de mediação educativa em museus foram compreendidas durante muito tempo como atividades complementares que se desenrolam nos espaços expositivos, implementadas por uma equipe de monitores ou guias (atualmente denominados de educadores ou mediadores), cuja principal finalidade era a de "explicar" ou mesmo entreter o público cativo, em geral, crianças em idade e contexto escolar, a respeito dos principais temas expressos nos discursos das exposições. Uma exposição museológica é um canal de comunicação que estabelece uma relação entre sua proposta expográfica e o público, caracterizando-se como uma representação visual e parcial do universo do conhecimento humano (VASCONCELLOS, 2007).

Em geral, esses discursos foram concebidos por especialistas (curadores) sem a necessária e desejável participação de uma equipe interdisciplinar que deveria envolver, numa concepção contemporânea, também os profissionais da área museológica e o público, considerando a perspectiva de um diálogo mais efetivo e necessário no interior de uma instituição que ainda necessita de práticas mais democráticas e inclusivas no que tange à sua política de aproximação com diferentes segmentos da sociedade. Entretanto, as instituições museológicas ainda são organismos verticalizados de produção do saber que acabam por se contrapor ao ritmo, ao diálogo e às relações que se produzem nos espaços de mediação educativa e nos processos de trabalho com comunidades específicas.

Nessa direção Bourdieu, em seus diferentes trabalhos (1983; 1989), trouxe chaves analíticas para se compreender as relações de poder em torno do campo científico. Segundo o autor, não existe neutralidade na produção do conhecimento, mas uma dinâmica repleta de conflitos, interesses políticos, disputas e manutenção dos lugares de privilégio. Essa estrutura reitera hierarquias, como também privilegia determinados temas e definições do que é ou não ciência. Bourdieu desenvolve a noção de campo, que possui lógica própria, com diferentes disputas por posições/espaços entre dominantes e dominados, tal como no campo das artes, moda, religião, escola, ciência, e dos museus, entre muitos outros. A partir disso, compreendemos então os esforços em aprofundar e dar visibilidade ao trabalho educativo comunitário no interior das instituições museológicas.

$\begin{array}{llllll}\text { (C) ETD-Educação Temática Digital } & \text { Campinas, SP } & \text { v.20 } & \text { n.3 } & \text { p.623-639 } & \text { jul./set. } 2018\end{array}$


[...] uma vez que este evidencia a disputa que existe entre as formas dominantes de produção e representação do conhecimento e a transmissão de valores culturais versus a busca de formas alternativas de construção e apropriação coletiva do conhecimento, em especial aquele que é o resultado do diálogo intercultural entre os saberes que resultam desse processo. (CEVALLOS; MACAROFF, 2015, p. 2, tradução nossa)

Bourdieu e Darbel (2007), em um estudo sociológico de públicos frequentadores de museus de arte em alguns países europeus, refletem as intrínsecas relações entre o capital econômico e o capital cultural. Os museus estão abertos a todos, porém, não são visitados por todas as parcelas da sociedade. A cultura é construída socialmente, e o acesso a esta não é um privilégio natural, mas sim produzido e ampliado à medida que cresce o nível de instrução educacional. Essa pesquisa, realizada pelos autores no final da década de 1960, ainda se faz atual, afinal, não basta que os museus sejam públicos e gratuitos, há diversas barreiras invisíveis e simbólicas que impedem diferentes setores e pessoas a acessarem e usufruírem desses locais. Cabe às instituições museológicas criarem estratégias internas e externas para abrir esse locus a outras percepções e realidades culturais.

Neste momento, é preciso considerar que o processo de mediação em espaços museais ocorre tanto no interior dessas instituições para públicos cativos - escolares, terceira idade, especiais -, e denominado atualmente de mediação educativa, como aquele que ocorre para além dos muros dos museus e que pode ser referenciado como mediação comunitária colaborativa (LANDKAMMER, 2015). No caso específico desse projeto e alvo desta reflexão assumimos, portanto, esta última categoria como a mais adequada a esse tipo de ação educativa nos espaços de vulnerabilidade social.

É necessário portanto esclarecer que a mediação comunitária colaborativa pode ser compreendida como uma modalidade de atuação, que parte do estabelecimento de um projeto conjunto entre diferentes atores, considerando distintos interesses e relações de poder, que pode trazer modificações efetivas para todos os envolvidos, especialmente a comunidade com a qual se trabalha e a ressignificação do museu (LANDKAMMER, 2012).

Nessa perspectiva, a mediação comunitária se volta para articular demandas e aspirações coletivas, gerando condições para o diálogo e a participação frente às políticas institucionais e culturais; além de reconhecer as tensões de poder e as possibilidades de transformação que implicam a relação entre um organismo cultural e a sociedade. A relação entre museus e a comunidade com a qual se trabalha na perspectiva colaborativa compreende, ainda, uma relação diferente daquela de coparticipação, uma vez que a primeira implica a definição de uma ação efetivamente conjunta a partir dos interesses de ambos os atores-instituições-entidades envolvidos, enquanto a segunda pressupõe uma estrutura estabelecida apenas a partir da instituição promotora e, dessa maneira, seu interesse acaba se sobrepondo ao da comunidade (LANDKAMMER, 2015).

Ao optarmos por essa perspectiva de mediação comunitária do trabalho educativo em museus, a questão do processo de aprendizagem mútuo e a construção do conhecimento assumem outras implicações e contradições que discutiremos a seguir.

(C) ETD-Educação Temática Digital $\quad$ Campinas, SP $\quad$ v.20 $\quad$ n.3 $\quad$ p.623-639 jul./set. 2018




\section{A FAVELA ESTÁ PARA A UNIVERSIDADE, ASSIM COMO A UNIVERSIDADE ESTÁ PARA A FAVELA. O PROJETO GIRASSOL DO MUSEU DE ARQUEOLOGIA E ETNOLOGIA DA USP}

O Museu de Arqueologia e Etnologia possui uma extensa história no desenvolvimento de ações educativas, destacando-se no âmbito dos museus antropológicos. As chamadas ações educativas remontam e estão entrelaçadas ao surgimento da própria instituição, relacionadas ao Instituto de Pré-História, desde 1978 (BRUNO, 1984), e ao antigo Museu de Arqueologia e Etnologia da USP, desde 1981 (HIRATA, 1985; 1989), que forneceram as bases para o trabalho atual a partir da fusão de ambos em $1989^{3}$. Ao longo dessa história o setor educativo dessa instituição teve um papel de destaque, evidenciado pelos processos de concepção de exposições, que desde o início integrou educadores e diferentes profissionais. Os trabalhos realizados podem ser considerados pioneiros nas ações educacionais no âmbito dos museus universitários, destacando-se também o protagonismo no que tange à socialização do patrimônio arqueológico dentro da prática arqueológica, denominada mais tarde no país como educação patrimonial e arqueologia pública (CARNEIRO, 2009; WICHERS, 2010).

Atualmente a área Educativa do Museu está estruturada em diferentes programas, que se organizam a partir desse histórico de ações e por meio dos novos dilemas e desafios institucionais ${ }^{4}$. No Programa de Acessibilidade trabalhamos com diferentes linhas de atuação e compreendemos o termo de forma ampla, que abarca desde o movimento do Museu se tornar acessível para pessoas com deficiência física, até romper barreiras internas e externas que promovam o acesso de pessoas em situações de vulnerabilidade social ${ }^{5}$. A discussão da acessibilidade de diferentes públicos aos espaços museológicos tem crescido nas últimas décadas (SARRAF, 2013; OLIVEIRA, 2015; TOJAL, 2007), e o MAE a partir dessas reflexões vem desenvolvendo ações que buscam tornar os museus mais acessíveis para públicos com necessidades específicas. Cabe destacar a noção de acessibilidade universal, incluída pelo Estatuto de Museus, que orienta às instituições desenvolverem ações efetivas para adaptações em suas sedes e para a concepção de programas que contemplem diversos

\footnotetext{
${ }^{3}$ O Museu de Arqueologia e Etnologia surgiu em 1989 por meio da fusão do Instituto de Pré-História e do antigo Museu de Arqueologia e Etnologia da USP, além da incorporação do acervo etnográfico Plínio Ayrosa do Departamento de Antropologia da Faculdade de Filosofia, Letras e Ciências Humanas e dos componentes arqueológico e etnográfico do Museu Paulista.

${ }^{4}$ O Programa de Mediação oferece visitas orientadas nas exposições temporárias, na Reserva Técnica Visitável e oficinas no período de férias escolares. O Programa de Formação oferece cursos para professores e capacitação profissional para bolsistas e estagiários. O Programa de Recursos Pedagógicos concebe e desenvolve materiais educativos que são emprestados às escolas como recursos didáticos; e o Programa de Ações Extra Muros desenvolve atividades fora do espaço do Museu por meio de palestras, cursos em outras instituições, assim como participação em projetos de pesquisa acadêmica, nas áreas de arqueologia, etnologia e museologia. ${ }^{5}$ Entende-se esse conceito relacionado a diversos fatores sociais, econômicos e culturais que colocam em vulnerabilidade pessoas, coletivos e comunidades. Desde a década de 1980, foram atribuídos muitos significados e abordagens ao termo por diferentes áreas, sendo categorizados em três dimensões, como as noções de risco, de capacidade de enfrentamento dos riscos e de potencial de recuperação dos danos (SCHUMANN, 2014, p. 131).
}

$\begin{array}{llllll}\text { (C) ETD-Educação Temática Digital } & \text { Campinas, SP } & \text { v.20 } & \text { n.3 } & \text { p.623-639 } & \text { jul./set. } 2018\end{array}$ 
públicos (IBRAM, 2018) . Nessa direção, no MAE é realizada a Ativa Idade que desenvolve ações com o público da terceira idade desde os anos 2000 (ELAZARI, 2009); o MAE para Todos que trabalha com o público com deficiência visual desde 2009 (VASCONCELLOS, CARNEIRO, ELAZARI, DEBLASIS, 2009); e o Projeto Girassol que se dedica ao público de crianças atendidas pela ONG Espaço Girassol na comunidade Jardim São Remo (VASCONCELLOS, 2010; VASCONCELLOS, SILVA, 2017).

No caso específico do Museu de Arqueologia e Etnologia da USP, é necessário compreender o surgimento da Universidade para refletir criticamente sobre as imbricadas e problemáticas relações com o Jardim São Remo. A USP foi oficialmente fundada em 1934, agregando outras faculdades que já funcionavam anteriormente, como a Faculdade de Direito, a Escola Politécnica, a Faculdade de Medicina, a Escola Superior de Agricultura, a Faculdade de Farmácia e a de Odontologia, e nesse momento foi também surgiu a Faculdade de Filosofia, Ciências e Letras (BARROS, 2003, p. 165). Em meados da década de 1960, outros cursos foram abertos e foi intensificada a construção efetiva do campus Armando de Salles Oliveira localizado no bairro do Butantã, na cidade de São Paulo. No período da Ditadura Militar (1964-1985), parte das faculdades foi transferida para a atual localização, e o projeto do campus universitário foi ampliado, sobretudo com a construção de novos prédios e espaços de circulação.

Trabalhadores migrantes, principalmente do Nordeste, vieram em busca de melhorias de vida em São Paulo e muitos foram trabalhar nas obras da Cidade Universitária. Com a abundância de terreno, essa população passou a ocupar a região e iniciou-se o movimento de luta por moradia, estabelecendo os primeiros espaços do Jardim São Remo. Na década de 1980, a pesquisa de Blay e Martins (1980) demonstrou a proliferação de favelas no entorno da USP, sobretudo de trabalhadores da Universidade que moravam nessa localidade devido aos baixos salários e o alto preço dos aluguéis. Cabe destacar que as autoras já sinalizavam que, no processo de favelização dos funcionários da USP, encontravam-se prestadores de serviços, especialmente das empresas de construção civil. Esse cenário se configura ainda hoje como uma marca vigente de seus moradores, com uma parte considerável de terceirizados que atuam em serviços relacionados à limpeza e segurança. Portanto, a comunidade possui intrínsecas relações com a Universidade desde o seu surgimento até os dias atuais, com diferentes momentos de disputas e conflitos em torno desse espaço.

Entre 1995 e 1997, a Reitoria da USP decidiu pela construção de um muro, que passou a separar física e simbolicamente as duas realidades (FÁBIO, 2016). Os moradores da São Remo, em contraponto às suas casas e ruas apertadas, veem a USP como um local amplo, arborizado e frequentado por uma comunidade classe média, branca e escolarizada. Por sua vez, essa Universidade em diferentes escalas percebe a comunidade como um local de possibilidade de implementação de projetos ou um local de marginalidade que precisa ser

\footnotetext{
${ }^{6}$ O Estatuto de Museus foi lançado pelo decreto presidencial no 8.124, de 17 de outubro de 2013, que regulamenta a Lei 11.904/2009 e busca preservar o patrimônio cultural musealizado, orientar as ações do setor e fornecer ao Instituto Brasileiro de Museus (IBRAM) o papel fiscalizador.
}

$\begin{array}{llllll}\text { (C) ETD-Educação Temática Digital } & \text { Campinas, SP } & \text { v.20 } & \text { n.3 } & \text { p.623-639 } & \text { jul./set. } 2018\end{array}$ 
controlado pela força policial. Duas paisagens distintas, separadas por um muro e permeadas por contradições que colocam em discussão qual o papel social de uma universidade pública.

Antes do erguimento desse muro, as crianças e adolescentes da comunidade frequentavam mais intensamente o campus realizando diferentes atividades de lazer, como coletar frutos, jogar futebol, passear de ônibus circular gratuito, praticar trabalhos informais para alcançar algum sustento, empinar pipa, nadar na raia olímpica e no espelho d'água da Praça do Relógio (ROCHA, 2016, p. 76). Essa presença de crianças e jovens na Universidade trouxe muitos conflitos e problemas para a comunidade acadêmica, que não soube lidar com a situação. Com a morte controversa de um adolescente ocorrida na raia olímpica em 1997, a Universidade criou no ano seguinte o projeto Avizinhar, numa tentativa de estabelecer um diálogo ${ }^{7}$ com crianças e adolescentes moradores do Jardim São Remo. ${ }^{8}$

No início dos anos 1990, o Museu de Arqueologia e Etnologia da USP ocupou a atual sede, tornando-se uma das instituições mais próximas da comunidade São Remo. Essa mudança também gerou conflitos com os jovens do Jardim São Remo, pois em uma parte da área destinada ao Museu funcionava uma quadra de futebol que teve de ser desalojada. Em um fim de semana o MAE foi depredado e furtado como reação, e assim logo foram desenvolvidas ações para se aproximar do Jardim São Remo de maneira contínua (VASCONCELLOS, 2010). Uma autocrítica em relação ao início desses trabalhos está relacionada ao fato de que o Museu passou somente a ver a comunidade após esse conflito, com a resposta da comunidade apontando que faltou diálogo entre as duas realidades antagônicas, a favela e a Universidade. Isso abriu a sensibilidade da instituição para essa parcela da sociedade, mas a ação não partiu dela. Assim como hoje, outros departamentos da Universidade que realizam diferentes trabalhos de extensão não incorporam a comunidade como parceiros.

Em 2013 fomos procurados pela direção da ONG Espaço Girassol para retomar o trabalho junto ao MAE, uma vez que havia sido interrompido entre 2009 e 2013. Após esse momento, articulamos um projeto conjunto entre os interesses mútuos das duas instituições. A ONG estava trabalhando para cada ano escolar os seguintes eixos temáticos: quem eu sou; quem é o outro; onde estou; e como me torno um agente de transformação. Adotamos esses conteúdos de forma transversal, devido aos temas relacionados com as problemáticas do nosso acervo, fundamentalmente vinculado à diversidade cultural.

\footnotetext{
7 No mês de novembro de 1997, o morador da favela São Remo Daniel Pereira de Araújo, de 13 anos, foi encontrado morto na raia olímpica do campus da USP supostamente por afogamento. Houve testemunhas que apontaram que o menor havia sido espancado antes por seguranças da Universidade e, posteriormente, atirado nas águas da raia olímpica. A reação dos moradores foi de revolta com a destruição de alguns espaços do campus da USP.

8 O Programa Avizinhar foi uma ação inovadora da Universidade, que surgiu em 1998, voltada para entender e dialogar com crianças e jovens da comunidade São Remo, e nesse período atuou de muitas formas estreitando os laços de ambas. O Programa se encerrou em 2007.
}

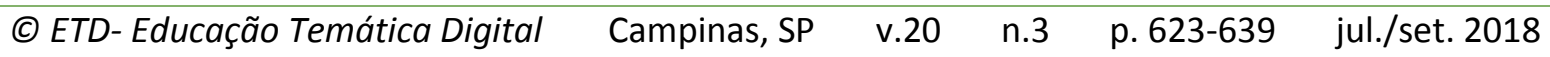


O trabalho foi retomado e, desde então, ações semanais são realizadas com um grupo de crianças em torno de 7 a 10 anos, por meio das áreas de arqueologia, etnologia e museologia. Como objetivos deste projeto (VASCONCELLOS, SILVA, 2017, p. 200) elencamos ${ }^{9}$ :

- Ampliar a função social de uma instituição museológica mediante o trabalho com públicos que geralmente não possuem acesso a esses espaços;

- Contribuir para o aprofundamento da relação entre a Universidade e as comunidades do seu entorno por meio de projetos de cultura e extensão;

- Aprofundar as discussões acerca do conceito de diversidade cultural na perspectiva de que a convivência com as diferenças culturais pode levar a sua compreensão e estabelecer um processo de interação social;

- Abordar a questão da alteridade por meio da aproximação dos nossos acervos com o repertório das crianças;

- Engajar as comunidades do entorno em relação ao seu território e aos espaços da Universidade, na luta pela melhoria das condições de seu espaço de moradia.

Entre os anos de 2014 e 2016 foram abordados diferentes temas centrais, propostos pela equipe do Museu tais como coleções e museus, prática arqueológica, patrimônio arqueológico, diversidade cultural indígena e africana, linguagem fotográfica, prática etnográfica e mapeamento do patrimônio local, Cidade Universitária e seus aparelhos culturais, história da cidade de São Paulo, problemas do Jardim São Remo, entre outros.

O grande desafio estabelecido foi promover e elaborar oficinas semanais que conciliassem diferentes temas de forma atrativa para um público infantojuvenil, que fossem articulados entre a Universidade e a comunidade, no caso, representada pela ONG Espaço Girassol. Nesse caso, o eixo condutor foi a proposição de ações que priorizassem atividades práticas sempre atreladas aos diferentes conteúdos. As crianças em todos os anos tiveram papel ativo no diálogo e proposição de ações, principalmente na sugestão de oficinas práticas, na escolha de locais a serem visitados e nos problemas identificados na comunidade e que precisariam mudar.

\footnotetext{
${ }^{9}$ Agradecemos a parceria e confiança da ONG Espaço Girassol, aos seus gestores e professores Rita Akinaga, Fernanda Matuda, Adelvan de Lima Nunes, Andreia, Samara e as crianças participantes Adriano Isidoro Santana, Ana Vitória de S. Silva, Aline Vitória da Silva, Daniel Matos Revoredo, Felipe Gabriel da C. De Souza, Julia Caroline da S. Gonçalves, Leticia Porfirio Bezerra, Maria Clara A. B. Rodrigues, Melissa Rodrigues Cavalcante, Myrela Vitória Vicente Santana, Nicolly de Souza Pereira, Nicolly Oliveira dos Santos, Renan de Souza Pereira, Rebeca Oliveira dos Santos e Ygor Rego Silva.
}

(C) ETD- Educação Temática Digital

Campinas, SP v. 20

n.3

p. $623-639$

jul./set. 2018 


\title{
3 OS DESAFIOS DA RELAÇÃO ENTRE O MUSEU E A COMUNIDADE NO PROCESSO DE MEDIAÇÃO COLABORATIVA
}

Temos clareza dos riscos e das implicações políticas quando decidimos implantar um processo de mediação comunitária colaborativa a partir do âmbito de uma instituição museológica e universitária. A primeira delas refere-se à postura paternalista, ou seja, a de que o museu, por "permitir" o acesso a algo tão "valioso" e distante desses grupos excluídos historicamente, pode pressupor erroneamente que a cultura existente nesses espaços sacralizados já seria relevante por si só (LANDKAMMER, 2015). Dessa maneira, esta oportunidade poderia ser confundida com uma experiência de levar o conhecimento a quem nada sabe ao mesmo tempo que permite ensinar modos de comportamento adequado ao permitir o contato com a cultura material ali representada. ${ }^{10}$

Ao mesmo tempo que há o risco de se cair nesse paternalismo aludido acima, a instituição assume uma falsa postura de democratizar esse acesso, pois, muitas vezes, é reforçada a relação hierarquizada da produção de conhecimento pelo seu corpo de curadores, e o que estes esperam do público visitante é uma atitude passiva de adesão à proposta curatorial, sem que lhe seja permitido o desenvolvimento de uma postura crítica que possa retroalimentar a proposta museológica das exposições e do potencial comunicativo do museu como um todo.

O processo comunicacional relacionado ao objeto cultural vai além da sua função tradicionalmente consagrada de transmitir uma mensagem predeterminada, e tem se voltado a outra direção, no sentido de uma nova relação baseada na interação entre o sujeito emissor (os profissionais do museu) com o sujeito receptor (o público participante). Nessa direção, Amanda Tojal reconhece um novo paradigma nos museus, pois, ao

\begin{abstract}
proporcionar uma interatividade mais ampla entre o objeto museológico e o seu público, as estratégias de mediação passam a redimensionar a forma de participação do sujeito receptor - de uma condição mais passiva, como assimilador de mensagem - para uma condição mais dialógica de participação ativa no processo de apreensão e de ressignificação do objeto cultural. (TOJAL, 2007, p. 88)
\end{abstract}

Nesse mesmo sentido, discussões contemporâneas referem-se à mediação como uma prática cultural específica que opera com problemáticas e dispositivos próprios (HONORATO, 2013; MORAES, 2014), entendendo suas complexas inserções institucionais, além do perigo da sua cooptação no âmbito de uma lógica neoliberal. As tendências atuais entendem a comunicação em museus como um processo cultural (HOOPER-GREENHILL, 2001) que acontece não em uma única via, mas em via dupla, dos especialistas até o público e do público aos especialistas. Nessa abordagem, o significado é construído por meio de um processo ativo

\footnotetext{
10 Segundo Meneses (1983, p. 112), por “*(...)cultura material poderíamos entender aquele segmento do meio físico que é socialmente apropriado pelo homem", e pode abarcar desde um vestígio até uma estrutura arquitetônica.
} 
de negociação de saberes e experiências, no qual todas as partes trabalham em conjunto para produzir interpretações compartilhadas.

Nessa perspectiva, todos aqueles que trabalham diretamente com os acervos museais podem ser referenciados como curadores, ampliando as possibilidades de atuação dos educadores dessas instituições. Segundo Mörsch (2015, p. 21), a educação em museus assim como a mediação educativa também devem ser reconhecidas no campo curatorial como prática cultural autônoma, de produção de conhecimentos.

No âmbito dessa discussão e do trabalho desenvolvido no Projeto Girassol, nos meses finais dos anos de 2014 e 2015, estabelecemos uma parceria com a museóloga do MAE Viviane Wermelinger Guimarães na proposição, concepção e realização de oficinas colaborativas, visando à construção conjunta de uma exposição intitulada "Pequenos Aprendizes do Museu de Arqueologia e Etnologia da USP", que foi montada e aberta pela comunidade do Jardim São Remo, na sede da ONG. A exposição, inaugurada na festa de confraternização e de encerramento das atividades do ano de 2014, apresentou as experiências vivenciadas pelas crianças, com as temáticas indígenas e afro-brasileiras. Já no ano de 2015, a exposição produzida "Passeando pelo Mundo" ocorreu na sede do MAE com a participação de 120 membros da comunidade, entre crianças, pais e moradores.

Nessas duas exposições, tudo foi selecionado e apresentado a partir do olhar das crianças, tais como a narrativa expográfica, a seleção de fotos, dos trabalhos realizados durante o ano, o percurso da exposição, as legendas, os textos explicativos e os créditos. Esse processo, ao mesmo tempo que consolidou um ano de trabalho, funcionou também como uma etapa de sua avaliação, pois permitiu a identificação do que havia se tornado significativo no decorrer de todo o trabalho conjunto.

Outro eixo de discussão desenvolvido com as crianças do projeto foi a temática relacionada com os diferentes usos e transformações das paisagens urbanas, partindo da exploração do Jardim São Remo, da Cidade Universitária e, por último, da cidade de São Paulo. Para isso, utilizamos a linguagem fotográfica ${ }^{11}$ para mapear os lugares significativos do Jardim São Remo com a participação do fotógrafo do MAE, Ader Gotardo, em que foram desenvolvidas diferentes oficinas, tais como construção poética de imagens, contato com os princípios fotográficos, a construção de uma câmera escura e o uso de câmeras descartáveis. Essa estratégia alcançou dois objetivos simultâneos ao ampliar repertórios pessoais no contato com a linguagem fotográfica, e também permitiu o estabelecimento de um processo de reflexão crítica sobre a própria realidade local. Foram identificados como patrimônio do Jardim São Remo o campo de futebol e a quadra esportiva; o Circo-Escola; o Supermercado Roldão Atacadista e o Espaço Girassol.

O campo de futebol e a quadra receberam a referência como bens patrimoniais por se constituírem como locais que mobilizam diferentes agentes da comunidade em muitas atividades, como os campeonatos de futebol aos fins de semana, e áreas de práticas de lazer

${ }^{11}$ Área central da cidade (Praça da Sé, Edifício Martinelli e CCBB), Instituto Tomie Ohtake e MAC-Ibirapuera.

(C) ETD-Educação Temática Digital $\quad$ Campinas, SP $\quad$ v.20 $\quad$ n.3 $\quad$ p.623-639 jul./set. 2018


como "empinar pipa, brincar de pega-pega, casinha", ou somente para se correr livremente em distintos jogos infantis. O Jardim São Remo em suas ruelas estreitas e tomadas por construções com poucas áreas de lazer encontra no "campinho" de chão batido um espaço de respiro e de junção de multifacetados agentes, cujos papéis são diluídos pelo lazer e pelo momento de descontração. Nesse sentido, interessante notar que as crianças ao chegarem para as atividades realizadas no Museu sempre negociaram conosco algum momento para que pudessem brincar no jardim. Independente da atividade realizada, esse espaço verde aparecia como mais atraente e interessante para elas. Em muitos momentos o simples brincar se tornava algo mais importante do que tratar de temas em torno da arqueologia ou da diversidade cultural.

O Circo-Escola, programa do Estado de São Paulo, é um marco na paisagem da favela. Com sua enorme tenda de lona azul e branca em uma das portarias de acesso entre o campus e o Jardim São Remo, se coloca imponente e chama a atenção por quem passa no local. São oferecidas diferentes atividades para crianças, jovens e adultos, e foi outro local escolhido como significativo para o grupo.

O Supermercado Roldão Atacadista, que está situado nos limites da comunidade na Avenida Corifeu de Azevedo Marques, foi escolhido como o local "das coisas gostosas" como biscoitos, iogurtes, doces, balas, entre outros produtos que são comprados pelos familiares. Esses itens habitam o imaginário de qualquer criança e têm seu espaço consagrado relacionado ao seu desejo de consumo.

Por fim, a ONG Espaço Girassol, local onde as crianças passam em torno de quatro horas diárias, é o espaço do afeto. O prédio se destaca da paisagem da comunidade, e possui um pátio interno que é o lugar preferido apontado por elas.

Esses quatros locais mapeados foram considerados pelas crianças como patrimônio, pois refletem e são resultados de apropriações simbólicas e concretas de desejos, vontades, e das relações afetivas com o próprio espaço. Essas diferentes apropriações e traduções da noção de patrimônio se materializaram nos lugares de lazer, de acolhimento, de acesso a gêneros alimentícios e estão intimamente conectadas com o modo e práticas da vida local.

Para ampliar a noção de uso e apropriação da paisagem urbana, acessamos diferentes espaços tanto da Cidade Universitária, como do centro histórico de São Paulo. Diferentes instituições museológicas e aparelhos culturais foram visitados, com a intenção de exercitar o direito à cidade, completamente desconhecida pelas crianças. Como fechamento desse eixo de trabalho propusemos às crianças a construção de uma maquete da cidade ideal para se viver. Elas elegeram então um museu, que neste caso foi o Museu de Arte Contemporânea da USP, especialmente com a obra do "gato" em grandes dimensões da artista plástica Nina Pandolfo; uma mansão com muitos cômodos, um submarino, um cinema, um parque de diversões, dois castelos de princesa, um dinossauro, um campo de futebol e o "relojão da USP", que é a Torre do Relógio localizada na Praça do Relógio da Universidade.

Também produzimos com as crianças um mapa do Jardim São Remo, da Cidade Universitária e da Cidade de São Paulo com todos os locais visitados, e solicitamos que
C ETD-Educação Temática Digital
Campinas, SP
v. 20
n.3
p. 623-639
jul./set. 2018 
colocassem outros que gostariam de experienciar. Foram elencados "cachoeira, coreto, parque de diversões, loja de pipas, pesqueiro, campo de futebol, piscina e cinema". Destacamos que estes três últimos espaços de lazer existem na Universidade, o Centro de Práticas Esportivas (CEPE-USP) e o CINUSP Paulo Emílio, porém o acesso e desfrute destes é vedado por restrições da Universidade.

A escolha desses espaços evidencia o quanto o contato com diferentes aparelhos culturais ao longo do ano, por meio de visitas a outros espaços, ampliou o repertório das crianças envolvidas, ao mesmo tempo que locais afetivos como o campo de futebol reaparecem marcando sua vivência de cidade ideal. A menção à existência de mansão e de castelos contrasta com a realidade vivida na comunidade, em casas e ruelas apertadas. Reitera o desejo e o sonho do direito a uma cidade diferente e a um modo de vida mais digno.

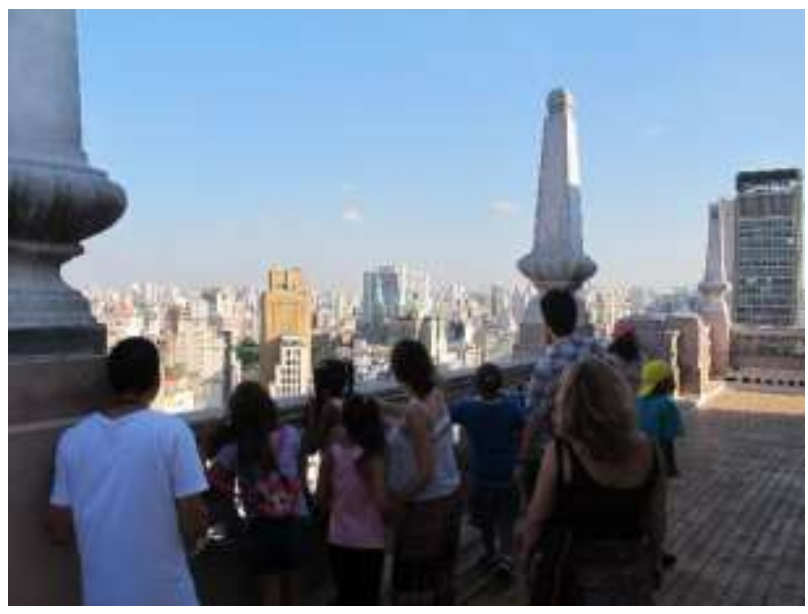

Figura 1. Crianças do Projeto Girassol observando o centro de São Paulo no terraço do Edifício Martinelli.

Fonte: Acervo Museu de Arqueologia e Etnologia da USP, 2015.

A utilização de métodos e estratégias da museologia para a concepção de um processo expográfico permitiu a todos os participantes que ocupassem o lugar do "curador", no sentido de elaborar um partido expográfico, selecionar as imagens, os objetos e a narrativa do processo. Esse trabalho, por sua vez, desmistificou o espaço de saber do museu, à medida que seus métodos foram apropriados pelas crianças participantes do processo de trabalho como um todo, ampliando a noção de mediação colaborativa. Essas ações se caracterizaram como um momento avaliativo do trabalho realizado ao longo dos anos de 2014 e 2015. Percebemos e identificamos, pela seleção do que expor, as ações mais significativas desenvolvidas, como por exemplo uma oficina de bordado realizada na exposição Histórias Mestiças em uma visita realizada ao Instituto Tomie Ohtake, entre muitas outras ações. Ressaltamos o papel de reflexão sobre o vivido, que a concepção de uma exposição colaborativa pode suscitar em todos participantes. Por sua vez no ano de 2016, como processo de fechamento do ano, concebemos de forma conjunta uma apresentação em slides 
para que apresentassem na festa de encerramento. Novamente estabelecemos um processo auto reflexivo e avaliativo sobre o trabalho. ${ }^{12}$

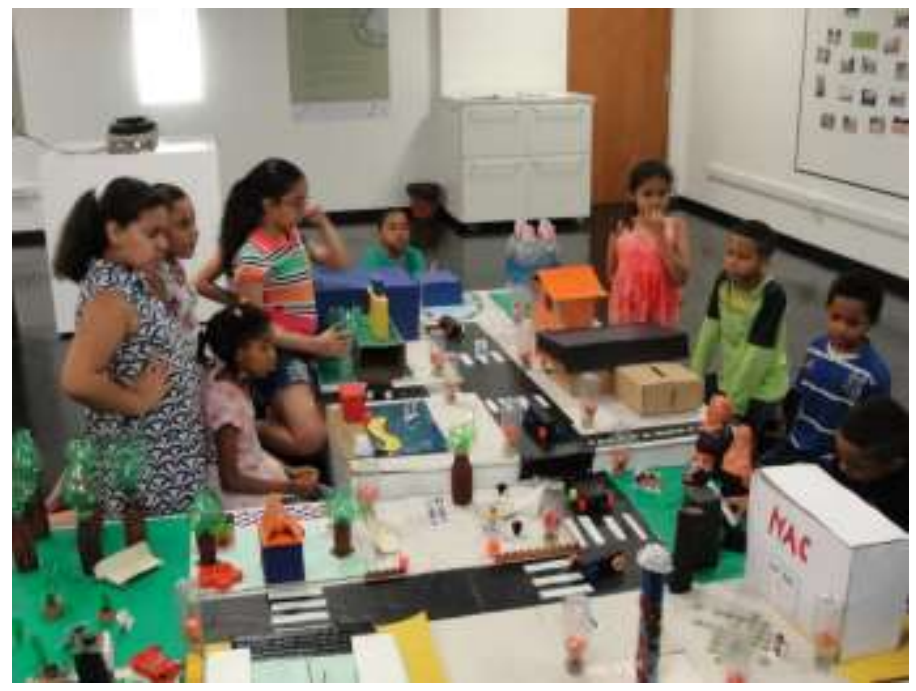

Figura 2. Crianças do Projeto Girassol realizando os últimos detalhes na maquete da Cidade dos Sonhos.

Fonte: Acervo Museu de Arqueologia e Etnologia da USP, 2015.

\section{ALGUNS APONTAMENTOS AVALIATIVOS DA MEDIAÇÃO COMUNITÁRIA}

O Projeto Girassol tem apresentado avanços positivos para os envolvidos diretamente, assim como para o Museu como um todo. Temos contado com o envolvimento de alunos de graduação por meio do Programa Unificado de Bolsas da Pró-Reitoria de Graduação e, de modo geral, essa aproximação com as ações é transformadora em relação à compreensão do papel social da instituição, assim como abre novas perspectivas profissionais e diferentes engajamentos com a comunidade. $O$ contato com as crianças ${ }^{13}$ da vizinhança da Universidade humaniza nossos espaços, e a formação que os bolsistas recebem passa a ter uma dimensão mais concreta e prática.

Para os trabalhadores terceirizados do Museu, especialmente das áreas de limpeza e de vigilância, ocorreu um impacto importante, ao passo que concorreu para a desconstrução da ideia de um museu como espaço elitista e destinado somente a certos grupos com maior capital econômico e cultural. Cabe destacar também alguns embates ocorridos com docentes e técnicos da instituição, que se viram incomodados com os ruídos considerados excessivos das crianças nas dependências da instituição. A mediação colaborativa permitiu que a

\footnotetext{
${ }^{12}$ Para além desse processo museológico, cabe destacar que ao final de toda atividade semanal realizamos um relatório reflexivo sobre as atividades realizadas. Apontamos todos os dilemas enfrentados pela equipe, assim como identificamos e planejamos estratégias potenciais futuras.

${ }^{13}$ Ananda Zendron e Diego Peralta do curso de Turismo, Júlia Galdino (Geografia), Juliana Alvarenga (Ciências Sociais), Márcia Strabelli (Terapia Ocupacional), Thaís Neves Macedo (Letras), que já participaram do projeto, e Vinicius Brahemcha (História) que participa atualmente.
}

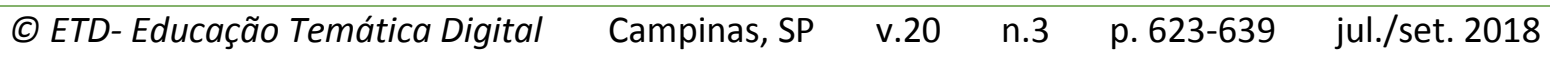


instituição e a comunidade São Remo se abrissem para repensar seus respectivos papéis sob a perspectiva de um Museu mais inclusivo com visitantes mais críticos e conscientes de seus direitos.

A realização de um trabalho sistemático e semanal com um mesmo grupo em um museu é importante para que possamos entender nossas ações para além das tradicionais visitas orientadas, em que determinado grupo de alunos tem uma experiência de duas horas. São postos desafios constantes para aprimorarmos nossa prática e por outro lado, pela dimensão de afeto criado entre todos os envolvidos, permite-se aprofundar diferentes temas em vários encontros. Outro grande ponto instigante para o Museu é ampliar a sua área de trabalho para assuntos que transcendem a sua esfera de atuação, como no nosso caso a arqueologia, a etnologia e a museologia. Por mais amplo que seja o escopo da museologia social, os profissionais da instituição devem estar com a escuta atenta para a incorporação de outras demandas, criando um espaço acolhedor, dinâmico e potente.

No caso das crianças envolvidas no projeto, passado um ano do término de trabalho contínuo com o mesmo grupo, nos reunimos para uma reflexão a respeito do que havia sido mais significativo dessa experiência, sendo citadas as visitas que ocorreram no centro da cidade de São Paulo, no Instituto Tomie Ohtake e no Museu de Arte Contemporânea. Além disso também foi referenciado o uso de múltiplas linguagens, como construção de maquetes, desenhos de observação de peças do acervo, escavação arqueológica simulada e a produção de animações em stop-motion.

Nessa mesma reunião foram selecionadas algumas imagens de atividades anteriormente realizadas para estimular a memória e as experiências vivenciadas. Novamente as visitas a outras instituições apareceram em sua grande maioria. Indagamos se após o trabalho realizado com o MAE tiveram interesse em visitar outros museus da cidade, sendo que todos demonstraram essa intenção, porém apenas três crianças visitaram outros museus como o Catavento Cultural, o Museu da Imagem e do Som e o Museu do Futebol, mediados pela escola. Esse dado indica a importância dos trabalhos dos museus com diferentes comunidades, para garantir o acesso efetivo a essas instituições.

\section{CONSIDERAÇÕES FINAIS}

O essencial de uma mediação museológica de perfil comunitário é o diálogo que se produz entre a experiência da visita ao museu e o cotidiano das pessoas, numa perspectiva de superação da exclusão e de uma atuação mais democrática e inclusiva. Outro grande desafio na implantação de uma mediação comunitária colaborativa diz respeito à construção de uma relação duradoura entre os educadores e os integrantes da comunidade com a qual se desenvolve o projeto. Essa é uma característica que o diferencia das rotineiras atividades e projetos que se desenvolvem com públicos tradicionais como os escolares, por exemplo, em que as atividades obedecem a uma lógica com um tempo limitado por agendas da própria instituição museal. 
Para o desenvolvimento dessa mediação comunitária colaborativa é necessário que as ações implementadas estejam baseadas numa lógica de construção permanente e de caráter sistemático, portanto, não se pode confundir com um evento temporário sob pena de desvirtuação de suas reais intenções e objetivos educativos.

Para o alcance desse propósito é fundamental o envolvimento não apenas dos educadores, mas também da própria instituição museológica, numa perspectiva interdisciplinar, abarcando os pesquisadores, museólogos e demais potenciais colaboradores, sem que o projeto restrinja ou limite o seu raio de ação apenas internamente. Nesse sentido, é importante a construção de um espaço que não se reduza à lógica do museu, nem à daquela comunidade envolvida; daí a originalidade de construir uma posição inovadora entre os diversos atores, especialmente no âmbito de uma instituição historicamente afastada da maioria da população.

A pergunta que este desafio procura responder diz respeito à firme intenção de que esta nova prática de mediação comunitária colaborativa estabeleça um processo crítico de produção de um conhecimento inovador, que possa alterar tanto a vida interna do museu como da própria comunidade envolvida, reconhecendo que não estamos lidando com a busca de um padrão hegemônico e homogêneo, mas sobretudo com conflitos e tensões que revelam e desvelam práticas excludentes historicamente.

É necessária a continuidade de trabalhos de extensão promovidos pela Universidade, mesmo com a falta de recursos públicos no âmbito dessa instituição. Da mesma forma, precisamos exercer nosso papel crítico em relação aos trabalhos de extensão, pois podemos cair no erro de reproduzirmos ações de "pacificação" dessa comunidade, que foge dos padrões culturais e econômicos dessa Universidade.

Ao terminar de escrever o artigo, indo embora do Museu em uma tarde de dezembro, no período de férias escolares, um grupo de quatro adolescentes jogavam bola no estacionamento de ônibus do lado externo do Museu. Jogando a bola que às vezes ia para a avenida, e eles desviavam felizes dos carros e ocupavam o campus universitário. Essa presença será constante na Universidade estando aberta ou não. Dessa forma, cabe a todos nós abrirmos nossas instituições e espaços de conforto para nos aproximarmos desses públicos e podermos aprender mutuamente.

\section{REFERÊNCIAS ${ }^{i}$}

BARROS, Lidia Almeida. A toponímia oficial e espontânea na Cidade Universitária - Campus Butantã da USP. Revista USP, São Paulo, n. 56, p. 164-171, 2003. Disponível em: https://www.revistas.usp.br/revusp/article/view/33818. Acesso em: 10 nov. 2017.

BLAY, Eva; MARTINS, Heloisa H. Souza. A favelização dos funcionários da USP. Ciência e Cultura, v. 32, n. 4, p. 418-420, 1980.

BOURDIEU, Pierre; DARBEL, Alain. $\mathbf{O}$ amor pela arte: os museus de arte na Europa e seu público. Trad. Guilherme João de Freitas Ferreira. 2. ed. São Paulo: Editora Zouk, 2007.
(C) ETD-Educação Temática Digital
Campinas, SP
v. 20
n.3
p. 623-639
jul./set. 2018 
BOURDIEU, Pierre. O poder simbólico. Lisboa: Difel; Rio de Janeiro: Bertrand, 1989.

BOURDIEU, Pierre. Coisas ditas. São Paulo: Brasiliense, 2004.

BOURDIEU, Pierre. O campo científico. In: ORTIZ, Renato (Org.). Bourdieu - Sociologia. São Paulo: Ática, 1983. p. 122-155.

BRUNO, Maria Cristina Oliveira. Museu do Instituto de Pré-História: um museu a serviço da pesquisa científica. Dissertação (Mestrado) - Faculdade de Filosofia, Letras e Ciências Humanas, Universidade de São Paulo, São Paulo, 1984.

CARNEIRO, Carla Gibertoni. Análise de ações educativas relativas a programas de resgate arqueológico. Tese (Doutorado em Arqueologia) - Museu de Arqueologia e Etnologia, Universidade de São Paulo, São Paulo, 2009.

CEVALLOS, Alejandro; MACAROFF, Anahi. Contradecires una misma. Museos y mediación educativa crítica. Quito: Fundación Museos de la Ciudad de Quito, 2015.

ELAZARI, Judith Mader. Ação educativa em museus: a terceira idade construindo conhecimentos a partir de objetos no MAE/USP. Revista do Museu de Arqueologia e Etnologia, Universidade de São Paulo, São Paulo, n. 19, p. 337-354, 2009.

FÁBIO, André Cabette. Como é a relação entre a Cidade Universitária e a comunidade São Remo. 2016. NEXO Jornal. Disponível em:

https://www.nexojornal.com.br/expresso/2016/09/06/Como-\%C3\%A9-arela\%C3\%A7\%C3\%A3o-entre-a-Cidade-Universit\%C3\%A1ria-e-a-comunidade-S\%C3\%A3oRemo. Acesso em: 20 out. 2017.

HIRATA, Elaine V. Relato das experiências educacionais do MAE: 1981-1982. Dédalo, São Paulo, n. 24, p. 11-20, 1985.

HIRATA, Elaine V. et al. Arqueologia, educação e museu: o objeto enquanto instrumentalização do conhecimento. Dédalo, São Paulo, n. 27, p. 11-46, 1989.

HONORATO, Cayo. Status e funções da mediação educacional da arte. Periódico Permanente, v. 2, p. (online), 2013. Disponível em:

http://www.forumpermanente.org/event pres/exposicoes/documenta-12-1/relato-sobrepalestra-debate-e-oficina-com-carmen-morsch . Acesso em: 10 nov. 2017.

HOOPER-GREENHILL, Eilean. The educational role of the museums. 2. ed. London; New York: Routledge, 2001.

IBRAM- Instituto Brasileiro de Museus. Presidência publica decreto que regulamenta o Estatuto de Museus. Disponível em: http://www.museus.gov.br/presidencia-publicadecreto-que-regulamenta-o-estatuto-de-museus/ Acesso em: 05 de abril de 2018.

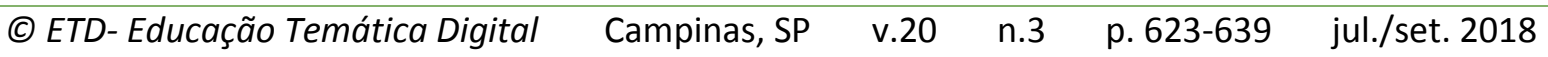


INSTITUTO SOCIOAMBIENTAL. Povo Mura. Disponível em:

https://pib.socioambiental.org/pt/povo/mura. Acesso em: 12 dez. 2017.

LANDKAMMER, Nora. Educación en museos y centros de arte como práctica colaborativa. In: CEVALLOS, Alejandro; MACAROFF, Anahi. Contradecires una misma. Museos y mediación educativa crítica. Quito: Fundación Museos de la Ciudad, 2015. p. 22-37.

LANDKAMMER, Nora. Colaboración, construcción de programas educativos. In: Diálogos sobre Educación Museística. Museo de Arte Contemporáneo de Santiago de Chile, Instituto Goethe, 2012. Disponível em: https://vimeo.com/52880895. Acesso em: dez. 2017.

MENESES, Ulpiano Toledo Bezerra de. A cultura material no estudo das sociedades antigas. Revista de História, São Paulo, n. 115, p. 103-117, dez. 1983. Disponível em: http://www.revistas.usp.br/revhistoria/article/view/61796. Acesso em: 10 dez. 2017.

MORAES, Diogo. Mediações em zigue-zague. Ocorrências institucionais e extrainstitucionais nas interações com públicos. Concinnitas, Revista do Instituto de Arte da UERJ, Rio de Janeiro, ano 15, v. 2, n. 24, p. 1-28, 2014.

MÖRSCH, Carmen. Contradecirse una misma, la educación en museos y mediación educativa como práctica crítica. In: CEVALLOS, Alejandro; MACAROFF, Anahi. Contradecires una misma. Museos y mediacion educativa crítica. Quito: Fundación Museos de la Ciudad, 2015. p. 10-21.

OLIVEIRA, Margarete de. Cultura e inclusão em museus: processos de formação em mediação para educadores surdos. Dissertação (Mestrado em Museologia) - Museu de Arqueologia e Etnologia da Universidade de São Paulo, São Paulo, 2015.

ROCHA, Mariana Machado. Quando a favela e a extensão da universidade: o Programa Avizinhar em meio às relações entre a USP e a São Remo. Dissertação (Mestrado em Educação) - Faculdade de Educação da Universidade de São Paulo, São Paulo, 2016.

SARRAF, Viviane Panelli. A comunicação dos cinco sentidos nos espaços culturais. Tese (Doutorado em Comunicação e Semiótica) - Pontifícia Universidade Católica de São Paulo, São Paulo, 2013.

SCHUMANN, Lívia Rejane Amaral. A multidimensionalidade da construção teórica da vulnerabilidade: análise histórico-conceitual e uma proposta de índice sintético. Dissertação (Mestrado em Desenvolvimento, Sociedade e Cooperação Internacional) - Centro de Estudos Avançados e Multidisciplinares, Universidade de Brasília, Brasília, 2014.

TOJAL, Amanda. Políticas públicas culturais de inclusão de públicos especiais em museus. Tese (Doutorado em Ciência da Informação) - Escola de Comunicação e Artes, Universidade de São Paulo, São Paulo, 2007.

VASCONCELLOS, Camilo de Mello. Imagens da revolução mexicana - O Museu Nacional de história do México. São Paulo: Alameda, 2007.
(C) ETD-Educação Temática Digital
Campinas, SP
v. 20
n. 3
p. $623-639$
jul./set. 2018 
VASCONCELLOS, Camilo de Mello. O papel social e educacional dos museus: um estudo de caso do projeto girassol do Museu de Arqueologia e Etnologia da USP. In: Silvania do Nascimento; Ana Paula Bossler (Org.). Museu-escola isto me lembra uma história. Belo Horizonte: UFMG, 2010, v. 1, p. 1-13.

VASCONCELLOS, Camilo de Mello; CARNEIRO, Carla Gibertoni; ELAZARI, Judith Mader; DEBLASIS, Paulo. O museu de arqueologia e etnologia da USP e o público especial. São Paulo: MAE-USP e Fundação Dorina Nowill para Cegos, 2009.

VASCONCELLOS, Camilo de Mello ; SILVA, Maurício André. A comunidade, a Universidade e a cidade de São Paulo por meio do olhar das crianças da São Remo: o trabalho socioeducativo do Museu de Arqueologia e Etnologia da Universidade de São Paulo. In: Romina Peralta; Alicia Loza. (Org.). Museos y archivos universitarios : educación, accesibilidad e inclusión : un debate necesario. La Plata: Universidad de la Plata, 2017, v. 1, p. 196-206.

WICHERS, Camila Azevedo Moraes. Museus e antropofagia do patrimônio arqueológico: (des)caminhos da prática brasileira. Tese (Doutorado em Museologia) - Universidade Lusófona de Humanidades e Tecnologias, Lisboa, 2010.

\footnotetext{
${ }^{\mathrm{i}}$ Revisão gramatical do texto sob a responsabilidade de: Juliana Flávia de Assis Lourenção Campoi Bacharel e Licenciada em Letras (FFLCH-USP) e Mestre em Linguística (FFLCH-USP) E-mail: jucampoi@gmail.com
} 